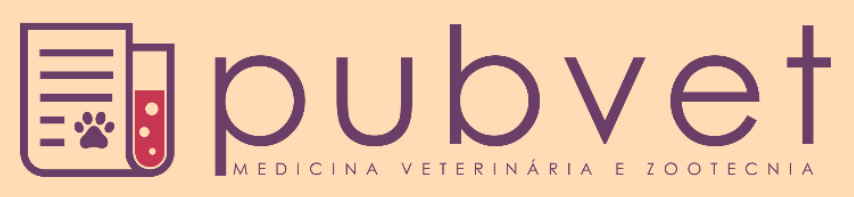

https://doi.org/10.31533/pubvet.v12n10a192.1-4

\title{
Intoxicação e morte por veneno de sapo em cão de Valença RJ: Relato de caso
}

\author{
Thalita de Freitas Durval ${ }^{10}$, Lilian Cristina de Sousa Oliveira Batista Cirne ${ }^{2 * \bullet}$ \\ ${ }^{I}$ Acadêmica da Faculdade de Medicina Veterinária de Valença do Centro de Ensino Superior de Valença/Fundação Educacional Dom André \\ Arcoverde (CESVA/FAA). Valença - Rio de Janeiro, Brasil.E-mail: thalitaveterinaria@yahoo.com.br \\ ${ }^{2}$ Médica veterinária, doutora em Ciências. Professora no Centro de Ensino Superior de Valençal Fundação Educacional Dom André \\ Arcoverde. Valença - Rio de Janeiro, Brasil. E-mail: lilian.batista@faa.edu.br \\ *Autor para correspondência
}

RESUMO. A cada ano, são atendidos vários casos de intoxicação exógena em animais domésticos nas clínicas e nos hospitais veterinários brasileiros. Sapos são capazes de causar envenamento em cães, devido ao veneno de alta toxicidade produzido e armazenado nas glândulas paratoides. Esse envenenamento pode causar a morte dos cães. O objetivo deste trabalho é relatar um caso de intoxicação e morte de um cão provocada por veneno de sapo do gênero Rhinella spp. no município de Valença-RJ. O animal foi atendido em clínica veterinária, após ingestão do veneno, e apesar da terapia instituída apresentou parada cardíaca e morte.

Palavras chave: anfíbio, envenenamento, toxina

\section{Intoxication and death by frog venom in a dog from Valença-RJ: Case report}

ABSTRACT.Each year, they are treated in several cases of exogenous intoxication in domestic animals in Brazilian veterinary clinics and hospitals. The attacks are capable of causing poisoning in dogs due to poison of high toxicity and are produced in the paratoid glands. This poisoning can cause dogs to die. The aim of this work was to relate a case of intoxication and death of a dog caused by frog venom of Rhinella spp. in the city of Valença-RJ. The animal was attended in veterinary clinic, after ingesting the venom, and although the therapy showed cardiac arrest and death.

Keywords: amphibian, poisoning, toxin

\section{Intoxicación y muerte por veneno de sapo en perro de Valencia RJ: Reporte de un caso}

RESUMEN. Cada año, se atienden varios casos de intoxicación exógena en animales domésticos en las clínicas y en los hospitales veterinarios brasileños. Los sapos son capaces de causar envenenamiento en perros debido al veneno de alta toxicidad producido y almacenado en las glándulas paratoides. Este envenenamiento puede causar la muerte de los perros. El objetivo de este trabajo es relatar un caso de intoxicación y muerte de un perro provocado por veneno de sapo del género Rhinella spp. en el municipio de ValençaRJ. El animal fue atendido en clínica veterinaria, después de la ingestión del veneno, ya pesar de la terapia instituida presentó paro cardíaco y muerte.

Palabras clave: anfibio, envenenamiento, toxina 


\section{Introdução}

Sapos podem causar intoxicações em cães por possuírem como mecanismo de defesa a secreção de um líquido rico em toxinas que fica armazenado em suas glândulas paratoides, também conhecidas como glândulas de veneno, sendo liberado apenas por compressão mecânica externa destas (Sakate \& Oliveira, 2000). Essa substância produzida por esses anfíbios possui composição química variável entre as espécies e pode ser altamente tóxica (Russel, 1986). O sapo Rhinella spp., mais conhecido como sapo cururu, pertence à família Bufonidae (Frost, 1985) e apresenta distribuição mundial, com maior frequência em regiões de clima tropical e úmido (Roberts et al., 2000). Em suas glândulas paratoides acumulam o "veneno", uma secreção mucoide esbranquiçada rica em toxinas cardiogênicas.

O veneno desses animais possui dois grandes grupos de substâncias ativas: as aminas biogênicas e os derivados esteroides (Zelnik, 1965). Das aminas biogênicas são destacadas, pela importância toxicológica, adrenalina, noradrenalina, serotonina, bufoteninas, dihidrobufoteninas e bufotioninas. Dos derivados esteroides, destacam-se os bufodienólides que podem ser divididos em bufogeninas e bufotoxinas, que agem de forma cardiotóxica, causando a inibição da bomba de sódio e potássio das células da musculatura cardíaca levando a um aumento da força de contração cardíaca e a redução dos batimentos cardíacos devido a uma ação do reflexo vagal (Chen \& Kovaříková, 1967; Eubig, 2001; Medeiros et al., 2009).

Os cães são as vítimas mais comuns devido à sua natureza inquisitiva, sendo atraídos pelos movimentos lentos do sapo, especialmente à noite (Osweiler, 1995). Eles atacam tais anfíbios e geralmente causam compressão das glândulas e consequente eliminação do veneno contido nas mesmas. A absorção de toxinas pela mucosa oral e gástrica ocorre rapidamente, podendo provocar a morte do animal 15 minutos após o aparecimento dos sinais clínicos. A morte dos cães intoxicados está relacionada ao efeito cardiotóxico do veneno levando à morte por fibrilação ventricular (MacDonald, 1990; Sakate \& Oliveira, 2000; Sonne et al., 2008). Os sinais clínicos incluem hipersalivação, mucosas hiperêmicas, apatia, vômitos, ansiedade, cegueira, taquipnéia e dor abdominal. Os animais podem apresentar sinais nervosos, incluindo convulsões, ataxia, nistagmo, opistótomo, estupor e coma (Roberts et al., 2000).

O objetivo deste trabalho é relatar um caso de intoxicação e morte de um cão provocada por veneno de sapo do gênero Rhinella spp. no município de Valença-RJ.

\section{Relato de caso}

Uma cadela SRD com sete anos de idade e 10,5 $\mathrm{kg}$ foi encaminhada à uma clínica veterinária particular localizada no município de Valença-RJ, após ter sido encontrada por sua proprietária mordendo um sapo diversas vezes. Ao exame clínico apresentava hipersalivação, mucosas hiperêmicas, apatia, vômitos sequenciais, ansiedade e taquipneia. Segundo a proprietária, o animal não apresentava nenhuma alteração anteriormente ao episódio.

Ainda no início do atendimento o animal começou a apresentar convulsões, ataxia, nistagmo, opistótono, estupor e coma.

O tratamento foi logo instituído e realizado com oxigenioterapia, fluidoterapia intravenosa lenta a base de $\mathrm{NaCl} 0,9 \%$, dipirona $(25 \mathrm{mg} / \mathrm{kg})$ para analgesia, furosemida $(1 \mathrm{mg} / \mathrm{kg})$ para promover a diurese e diazepam $(0,5 \mathrm{mg} / \mathrm{kg})$ para tranquilização e diminuição das manifestações neurológicas. Todos os fármacos foram administrados por via endovenosa. Foi realizada lavagem da boca do animal com água corrente e utilizadas compressas de água fria para diminuir a temperatura corporal do mesmo. $\mathrm{O}$ animal não apresentou remissão dos sinais e em seguida apresentou parada cardíaca. Foi instituído o uso de atropina $(0,02 \mathrm{mg} / \mathrm{kg})$, adrenalina $(0,05 \mathrm{mg} / \mathrm{kg})$, cloridrato de doxapram $(1 \mathrm{mg} / \mathrm{kg})$ e massagem para ressuscitação cardiopulmonar, mas apesar do tratamento estabelecido, o animal não resistiu aos efeitos do veneno e morreu cerca de duas horas após o início das manifestações.

O sapo responsável pela intoxicação apresentava corpo robusto, coloração bege-parda clara e manchas marrons escuras no dorso, bem como uma faixa médio-dorsal longitudinal de coloração clara, cristas cefálicas pronunciadas; glândulas paratóides grandes e pele de aspecto rugoso, compatíveis com o gênero Rhinella spp. (Condez et al., 2009). 


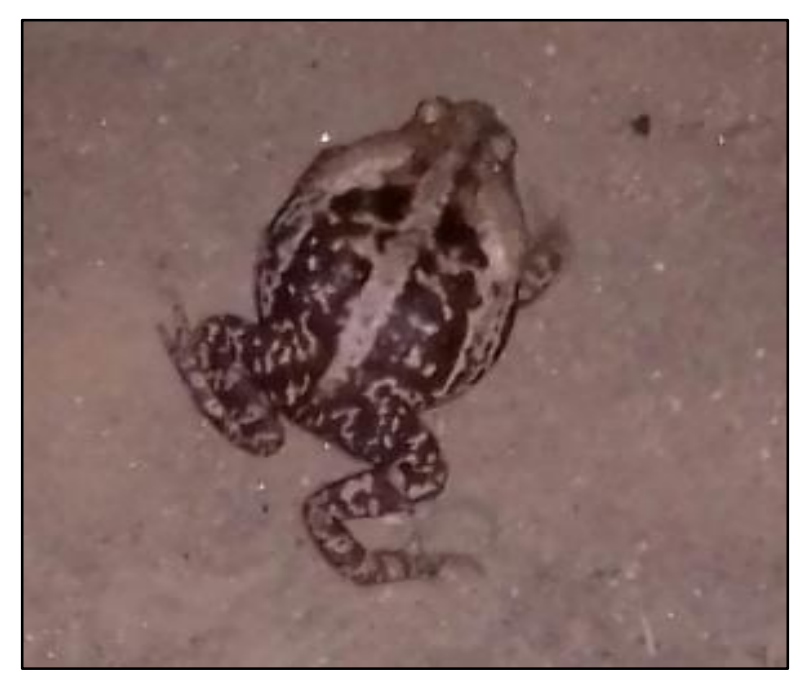

Figura 1. Sapo do gênero Rhinella responsável por intoxicação de cão.

\section{Discussão}

As características morfológicas apresentadas pelo sapo são compatíveis com a espécie Rhinella icterica (Condez et al., 2009; Hiert \& Moura, 2007) que de acordo com Condez et al. (2009) se distribui desde o sul e sudeste do Brasil até o norte da Argentina e leste do Paraguai.

A maioria dos casos de intoxicação por Rhinella spp. ocorre em cães de pequeno porte, como na cadela do presente relato, embora a letalidade seja baixa (Reeves, 2004). Segundo Guscio et al. (2007) e Barbosa et al. (2009) as toxinas agem mais intensamente nestes animais de pequeno porte, pois a quantidade de toxina é suficiente para causar intoxicação sintomática.

Os acidentes ocorrem especialmente nos arredores de lagos, reservatórios, riachos e rios, que são os habitats naturais desses anfíbios (Barbosa et al., 2009). Diferente do ocorrido no presente caso, em que o animal teve contato com o sapo em uma residência de área urbana. Valença é um município do Rio de Janeiro com extensas áreas de matas e coleções de água, sendo assim tutores devem estar atentos para evitar esse tipo de acidente, quando possível.

Os sinais clínicos apresentados pelo animal foram descritos por Roberts et al. (2000), no entanto a cegueira também referida pelos autores não foi comprovada neste caso. Embora a literatura ressalte que as bufotoxinas aumentam a concentração intracelular de cálcio ao bloquear a bomba de $\mathrm{Na}^{+}-\mathrm{K}^{+}$e que o animal consequentemente apresenta bradicardia ( $\underline{\text { Chen }}$ \& Kovaříková, 1967; Eubig, 2001; Zelnik, 1965), as catecolaminas presentes no veneno, como adrenalina e noradrenalina podem controlar esse efeito ( Sakate \& Oliveira, 2000).

O diagnóstico foi realizado com base no histórico e exame clínico como observado em outros trabalhos (Guscio et al., 2007; Salvago et al., 2009), até mesmo pela dificuldade de se chegar a resultados conclusivos em casos de intoxicações por zootoxinas.

Já com relação ao tratamento pode-se verificar, na literatura consultada, diferentes formas de tratamento e verificada a dificuldade em se estabelecer um protocolo adequado, e que dependendo do estágio da intoxicação, inclui a estabilização do paciente, a descontaminação e o uso de antiarrítmicos (Roberts et al., 2000). De acordo com Rabelo (2012) para o tratamento indica-se o estabelecimento de via aérea com oxigenioterapia, acesso venoso para administração de soluções cristaloides, lavagem de cavidade oral com água em abundância e utilização de diazepam $(0,5 \mathrm{mg} / \mathrm{kg})$ em caso de convulsões. A instituição de fluidoterapia e diurético também é recomendada na literatura (Barbosa et al., 2009; Reeves, 2004). Embora todo esse tratamento tenha sido instituído no animal do presente estudo, o mesmo não foi suficiente para reverter os sinais clínicos apresentados. Sugere-se que o tempo decorrido entre $o$ acidente e o atendimento o animal pode ter sido um dos fatores contribuintes para a morte do animal, assim como o seu pequeno porte, a quantidade de toxina absorvida e uma susceptibilidade individual.

$\mathrm{Na}$ literatura há muita divergência com relação ao uso dos fármacos para o tratamento dessas intoxicações, mas independente da escolha, o tratamento deve ser efetuado rapidamente, tendo em vista a gravidade da intoxicação (Ettinger \& Feldman, 2004; Palumbo et al., 1975). De acordo com a classificação apresentada por Sakate and Oliveira (2000), o quadro de intoxicação apresentado pelo animal do presente estudo pode ser considerado grave.

Não foi realizada necropsia do animal, no entanto, Osweiler (1995) relata que esse exame é inespecífico para esse tipo de intoxicação, revelando apenas alterações sugestivas, como hemorragias e congestão em diferentes órgãos, e não patognomônicas. 


\section{Conclusão}

Esse é o primeiro caso descrito de intoxicação por veneno de sapo no município de Valença-RJ. Embora não exista um antídoto contra as toxinas produzidas pelo sapo, é possível prevenir o contato dos cães com o anfíbio para evitar possíveis mordidas e compressões. Caso o contato ocorra, o cão deve ser levado imediatamente à uma clínica veterinária de pronto-atendimento.

Tutores precisam estar cientes de que a intoxicação por veneno de sapo deve ser considerada uma emergência devido ao risco de morte. Maiores estudos relacionados aos efeitos das toxinas de sapos em cães devem ser realizados, a fim de se chegar a protocolos terapêuticos de maior eficácia.

\section{Referências}

Barbosa, C. M., Medeiros, M. S., Riani Costa, C. C. M., Camplesi, A. C., \& Sakate, M. 2009. Toad poisoning in three dogs. Journal of Venomous Animals and Toxins including Tropical Diseases, 15(4), 789-798.

Chen, K. K., \& Kovaříková, A. 1967. Pharmacology and toxicology of toad venom. Journal of Pharmaceutical Sciences, 56(12), 1535-1541.

Condez, T. H., Sawaya, R. J., \& Dixo, M. 2009. Herpetofauna dos remanescentes de Mata Atlântica da região de Tapiraí e Piedade, SP, sudeste do Brasil. Biota neotropica, 9(1), 157185.

Ettinger, S., \& Feldman, E. 2004. Tratado de medicina interna veterinária: doenças do cão e do gato. Rio de Janeiro: Guanabara Koogan.

Eubig, P. A. (2001). Bufo species toxicosis: big toad, big problem. Veterinary Medicine, 96(8), 594599.

Frost, D. R. (1985). Amphibian species of the world (Vol. 1): American Museum of Natural History.

Guscio, C. G., Hossack, B. R., Eby, L. A., \& Corn, P. S. 2007. Post-breeding habitat use by adult boreal toads (Bufo boreas) after wildfire in Glacier National Park, USA. Herpetological Conservation Biology, 3(1), 55-62.

Hiert, C., \& Moura, M. O. 2007. Anfíbios do Parque Municipal das Araucárias (Vol. 1, pp. 1-41): Editora Unicentro, Guarapuava.

MacDonald, B. 1990. Terrier toad toxicity syndrome. Australian Veterinary Practitioner, 20(2), 118.
Medeiros, R. J., Monteiro, F. O., Castelo da Silva, G., \& Nascimento Júnior, A. 2009. Casos de intoxicações exógenas em cães e gatos atendidos na Faculdade de Veterinária da Universidade Federal Fluminense durante o período de 2002 a 2008. Ciência Rural, 39(7), 2105-2110.

Osweiler, G. D. 1995. Toxicology. Philadelphia: Lippincott Willian \& Wilkin, 443. Philadelphia: Lippincott Willian \& Wilkin.

Palumbo, N. E., Perri, S., \& Read, G. (1975). Experimental induction and treatment of toad poisoning in the dog. Journal of the American Veterinary Medical Association, 167(11), 10001005.

Rabelo, R. 2012. Emergências em pequenos animais: Condutas clínicas e cirúrgicas no paciente grave. Rio de Janeiro: Elsevier Brasil.

Reeves, M. P. 2004. A retrospective report of 90 dogs with suspected cane toad (Bufo marinus) toxicity. Australian Veterinary Journal, 82(10), 608-611.

Roberts, B. K., Aronsohn, M. G., Moses, B. L., Burk, R. L., Toll, J., \& Weeren, F. R. 2000. Bufo marinus intoxication in dogs: 94 cases (19971998). Journal of the American Veterinary Medical Association, 216(12), 1941-1944.

Russel, F. E. 198). Toxic effects of animal toxin. In L. J. Casarett \& J. Doulll (Eds.), Toxicology: the basic science of poisons (pp. 718-719. ). New York, USA: MacMillan Publishing Company.

Sakate, M., \& Oliveira, P. C. L. 2000. Toad envenoming in dogs: effects and treatment. Journal of Venomous Animals and Toxins, 6(1), 52-62.

Salvago, M. M. R., López, M. A. M., Benítez, L. J., Moya, R. P. J., Palacios, F. O. R., \& Sillero, C. L. N. 2009. Intoxicación aguda en perro por toxinas de sapo (Bufo bufo). REDVET. Revista Electrónica de Veterinaria, 10(4), 1-5.

Sonne, L., Rozza, D., Wolffenbuttel, A. N., Meirelles, A. E. W. B., Pedroso, P. M. O., Oliveira, E. C., \& Driemeier, D. 200). Intoxicação por veneno de sapo em um canino. Ciência Rural, 38(6), 1787-1789.

Zelnik, R. 1965. A natureza química do veneno de sapo. Ciências Cultos, 17, 10-14.

Recebido: 20 Julho. 2018

Aprovado: 16 Agosto. 2018

Publicado: 16 Outubro. 2018

Licenciamento: Este artigo é publicado na modalidade Acesso Aberto sob a licença Creative Commons Atribuição 4.0 (CC-BY 4.0), a qual permite uso irrestrito, distribuição, reprodução em qualquer meio, desde que o autor e a fonte sejam devidamente creditados. 